\title{
Desde una educación intercultural para pueblos indígenas hacia otra pertinente al contexto migratorio actual. Un análisis basado en el caso de Chile
}

\section{From an intercultural education for indigenous peoples to another one focused on the current migration context. An analysis based on the Chilean case}

\author{
Andrea Riedemann ${ }^{1}$ https://orcid.org/0000-0003-3604-1771 \\ Carolina Stefoni ${ }^{2}$ https://orcid.org/0000-0001-6949-2312 \\ Fernanda Stang ${ }^{3}$ https://orcid.org/0000-0003-3781-3024 \\ Javier Corvalán ${ }^{4}$ https://orcid.org/0000-0002-3782-8376 \\ ${ }^{1}$ Centro de Estudios Interculturales e Indígenas, Pontificia Universidad Católica de Chile, Santiago, \\ CHILE. Email: andreariedemann@gmail.com \\ ${ }^{2}$ Centro Sociedad Tecnológica y Futuro Humano, Universidad Mayor, Santiago, CHILE. \\ Email: cstefoni@gmail.com \\ ${ }^{3}$ Centro de Investigación en Ciencias Sociales y Juventud, Universidad Católica Raúl Silva Henríquez, \\ Santiago, CHILE. Email: fstang@ucsh.cl \\ ${ }^{4}$ Facultad de Educación, Universidad Alberto Hurtado, Santiago, CHILE. Email: jcorvala@uahurtado.cl
}

\section{Resumen}

El artículo plantea la pregunta de si el Programa de Educación Intercultural Bilingüe (PEIB), la política educativa chilena enfocada en aquellos grupos que históricamente han sido considerados como representantes de la diversidad cultural en el país -aquellos pueblos reconocidos por la Ley Indígena de Chile-, es aplicable al contexto relativamente nuevo que ha emergido en las escuelas a raíz de la migración internacional. Para ello, se presenta brevemente el origen del PEIB y el contexto en el cual emergió, un análisis de dos de sus características centrales, y una discusión sobre los eventuales vasos comunicantes de ese programa con el contexto migratorio. Mediante un análisis documental de los aspectos mencionados y de las evaluaciones hechas al PEIB, se llega a la conclusión de que es poco conveniente considerar esta política educativa como un punto de partida hacia una política pertinente a la realidad migratoria. Ante esa conclusión, se presentan al final algunas reflexiones sobre los desafíos a los que se enfrenta el sistema educativo chileno, profundamente inmerso en un modelo neoliberal de sociedad, para avanzar hacia una buena educación para todos, y que a la vez tenga en cuenta la diversidad cultural.

Palabras claves: educación intercultural, pueblos indígenas, migración, Chile.

\begin{abstract}
This article poses the question if the Intercultural Bilingual Education Programa of Chile (PEIB, for its name in spanish), the education policy designed for those groups that historically have been considered as representatives of cultural diversity -those groups recognized by the chilean Indigenous Law- is suitable for the rather new context that has emerged in schools due to international migration. The analysis presents the origin of PEIB and the context that made it possible, focuses on two central features of the PEIB, and then discusses the possible connection points with the new context. Based on a document analysis of the aforementioned aspects and some of the evaluations the program has gone through, we conclude that it is rather not recommendable to use the PEIB as a starting point for a education policy that attends to the migration context. At this point, the article presents some thoughts about the challenges the chilean education system -deeply rooted in a neoliberal society model- faces to advance towards a good education system for all, that also takes into account cultural diversity.
\end{abstract}

Keywords: intercultural education, indigenous peoples, migration, Chile.

Recibido: 3 noviembre 2017. Aceptado: 7 diciembre 2018 


\section{Introducción}

La migración es parte de las sociedades contemporáneas, y a la fecha, muy pocas regiones del mundo se encuentran ajenas a este fenómeno (Castles y Miller, 2004; Elizalde, Thayer y Córdova, 2013). También América Latina y el Caribe son escenario de intensos procesos migratorios, en los que tienen lugar todas las expresiones de la migración internacional contemporánea: emigración, inmigración, retorno, migración irregular, desplazamiento forzado y búsqueda de refugio, sumado a la presencia de nutridas comunidades en el exterior (Canales y Zlolniski, 2001; Martínez, 2011). Si bien en el marco de los estudios migratorios tradicionalmente América Latina ha sido analizada como región de emigración, los antecedentes actuales hablan a favor de analizar con el mismo interés la migración intrarregional, que da muestras de una gran vitalidad (Martínez y Orrego, 2016).

Dentro de la región, Chile es uno de aquellos países en los cuales la inmigración latinoamericana y del Caribe está aumentando sostenidamente desde la década del noventa. Si bien esta migración está compuesta principalmente de personas adultas, conlleva también la migración de niños y jóvenes en edad escolar, quienes en el corto o mediano plazo han estado incorporándose a los establecimientos educacionales del país (Stefoni, Acosta, Gaymer y Casas-Cordero, 2008). Esto ha implicado la presencia, al interior de las escuelas y los liceos, de nuevas nacionalidades, etnias, lenguas, colores de piel y costumbres, entre muchos otros aspectos que hablan de la creciente diversidad cultural que se ha instalado en los establecimientos.

En aquellos países que llevan más tiempo enfrentados al fenómeno migratorio -entre ellos, los así llamados clásicos países migratorios (Koopmans, 2013) - la respuesta preferente frente a la diversidad social y cultural del alumnado ha sido la transición hacia una educación intercultural o multicultural, dependiendo del uso que se da a cada uno de estos conceptos en las diferentes regiones del mundo (Palaiologou y Dietz, 2012). Preliminarmente, entendemos como una educación de ese tipo aquella que "desafía y rechaza el racismo y otras formas de discriminación en la sociedad y en la escuela, y acep- ta y afirma el pluralismo (étnico, racial, lingüístico, religioso, económico, de género y otros), que los y las estudiantes, sus comunidades y los y las profesoras representan" (Banks, 1995, citado en Poblete, 2009, p. 190).

Con base en las evidencias que la investigación realizada en establecimientos chilenos con alto porcentaje de matrícula migrante ha levantado, las y los autores del presente artículo compartimos la convicción de que también en Chile es relevante que se avance cuanto antes hacia una educación que tenga en cuenta el contexto migratorio, y que en este proceso la incorporación del concepto de interculturalidad es pertinente. ${ }^{1}$ Pero no cualquier concepto de interculturalidad sirve a este propósito. En América Latina, "hablar de interculturalidad implica una conversación larga y complicada", que significa "enfrentar el trauma de la conquista y esclavitud. Estas realidades históricas preceden y están en la base de los Estados que surgirán al comienzo del siglo XIX y de los sistemas escolares que les siguieron" (Johnson, 2015 , p. 8). En línea con ese argumento, dentro de la amplia gama de definiciones existentes consideramos que para Chile y Latinoamérica son especialmente relevantes los planteamientos de la interculturalidad crítica. Los representantes de este enfoque destacan la importancia que ha tenido en América Latina su pasado colonial, y en consecuencia relevan el rol que ha jugado el pensamiento colonialista en las relaciones e interacciones sociales de quienes conviven en esta región del mundo. Dicho pensamiento está permeado por una mirada racializada de la sociedad, "con los blancos y 'blanqueados' en la cima y los pueblos indígenas y afrodescendientes en los peldaños inferiores" (Walsh, 2010, p. 78). La interculturalidad crítica se entiende como "proyecto político, social, ético y epistémico - de saberes y conocimientos-, que afirma la necesidad de cambiar no solo las relaciones, sino también las estructuras, condiciones y dispositivos de poder que mantienen

1 En este punto es relevante mencionar que a partir de la Ley General de Educación (LGE) del año 2009, este concepto ya existe como principio que inspira el sistema educativo chileno. La LGE en su artículo $3^{\circ}$, letra $\mathrm{m}$, establece lo siguiente: "Interculturalidad: El sistema debe reconocer y valorar al individuo en su especificidad cultural y de origen, considerando su lengua, cosmovisión e historia" (Mineduc, 2009). 
la desigualdad, inferiorización, racialización y discriminación" (Walsh, 2010, p. 79).

La interculturalidad crítica se distingue de otra manera de entender la interculturalidad y que ha sido denominada "funcional": en esta última, "la perspectiva de interculturalidad se enraíza en el reconocimiento de la diversidad y diferencia culturales, con metas a la inclusión de la misma al interior de la estructura social establecida. Desde esta perspectiva [...] la interculturalidad es 'funcional' al sistema existente, no toca las causas de la asimetría y desigualdad sociales y culturales, tampoco 'cuestiona las reglas del juego'; por eso 'es perfectamente compatible con la lógica del modelo neo-liberal existente" (Tubino, 2005, citado en Walsh, 2010, pp. 77-78). El sistema y el modelo que la cita precedente menciona, se vinculan estrechamente con el hecho de que la manera que muchos países latinoamericanos han encontrado para relacionarse con los pueblos indígenas a partir de la apertura al capitalismo global es la del multiculturalismo neoliberal. El Programa de Educación Intercultural Bilingüe en Chile emergió justamente en este contexto en el que comenzaban a conjugarse multiculturalismo y neoliberalismo, y tal como se verá con mayor detención más adelante, una serie de elementos llevan a concluir que el significado de la interculturalidad que se desprende de dicho programa corresponde mucho más a la vertiente funcional que a la interculturalidad crítica.

En el presente artículo, y siguiendo los planteamientos de la interculturalidad crítica, cuando decimos "educación intercultural pertinente al contexto migratorio", el vocablo "pertinente" no solo se refiere a que la educación debe considerar la diversidad asociada a la migración internacional, sino también a que debe hacerlo teniendo en cuenta que Chile, como toda América Latina, tiene un pasado colonial, y que hasta el día de hoy gran parte de la población se guía por la lógica de la colonialidad (Quijano, 2001; Mignolo, 2007).

Son diversos los actores ${ }^{2}$ que abogan por introducir en el sistema educativo chileno un enfoque nuevo,

2 Ver por ejemplo Declaración de la Mesa por una Educación Intercultural (http://priem.cl/?p=588), propuestas de la Universidad de Chile (2015), propuestas prove- pertinente a la creciente diversidad asociada a la migración. El Ministerio de Educación (Mineduc), el del Interior y el de Justicia, además de la Superintendencia de Educación de Chile, han promulgado normas relativas a facilitar el acceso y la matrícula de los alumnos extranjeros (Jiménez, Aguilera, Valdés y Hernández, 2017), además de orientaciones técnicas y otros documentos relacionados (Mineduc, 2017b; Ramírez y Miranda, 2018), pero no se ha elaborado hasta la fecha una política educativa integral dirigida a abordar en todas sus aristas el desafío que conlleva la diversificación del alumnado por motivos migratorios. ${ }^{3}$

Ante la existencia de una política educativa intercultural -la que, como ya se planteó, fue diseñada originalmente para las poblaciones indígenas reconocidas por la Ley Indígena de Chile- emerge la pregunta de si esa política educativa es transferible a un contexto marcado por la migración. En concreto, la pregunta que el presente artículo busca responder es si el Programa de Educación Intercultural Bilingüe (PEIB) que se ha desarrollado en Chile es un punto de partida adecuado para avanzar hacia

nientes del ámbito académico (Stefoni, Acosta, Gaymer y Casas-Cordero, 2008; Poblete, 2009; Jiménez, 2014; Bustos y Gairín, 2017), materiales vinculados al Observatorio Chileno de Inclusión Educativa Migrante (www.educacionymigracion.cl), la conformación del Anillo "Inmigrantes en el Sistema Educacional Chileno Anillo" de la UCM (http://migrantes.cl), entre otros.

3 Durante el primer semestre de 2018 el Ministerio de Educación publicó el documento "Política Nacional de Estudiantes Extranjeros 2018-2022” (Ministerio de Educación, 2018b), pero a pesar de lo que el nombre del documento anuncia, su contenido corresponde más a un diagnóstico que a lineamientos políticos. Cabe señalar que la inexistencia de una política educativa integral frente a la migración en realidad no debiera sorprender en un país cuya Constitución no se reconoce ni multicultural ni plurinacional, y donde la normativa migratoria vigente data del año 1975: fue promulgada en los primeros ańos de la dictadura militar encabezada por Augusto Pinochet (1973-1990), en línea con la así llamada doctrina de la seguridad nacional, y básicamente considera - hasta el día de hoy- al extranjero como un eventual peligro para la sociedad chilena. En mayo de 2018, el presidente Piñera dio urgencia simple a la discusión en el Parlamento al proyecto de ley sobre esta materia que ya había presentado durante su mandato anterior, en el año 2013, pero a la fecha de revisión del presente artículo, dicha discusión aún no se había iniciado. 
una educación intercultural pertinente al actual contexto migratorio del país.

Junto a la relevancia que tiene esta reflexión para el sistema educativo chileno, puede ser de interés para diferentes actores vinculados a otros sistemas educativos de América Latina y el Caribe, desde los cuales en la actualidad proviene una cantidad considerable de niños y jóvenes que se insertan en escuelas y liceos chilenos. Además, dado que la migración es un fenómeno global y dinámico, posiblemente en un tiempo más otros países de América Latina se vean interpelados a discutir cómo hacer avanzar sus respectivos sistemas educativos hacia la interculturalidad en un contexto migratorio, y la discusión que en la actualidad se da en Chile podría representar un antecedente de utilidad. Por otra parte, la reflexión que se presenta profundiza la incorporación del caso chileno a un debate más amplio y global sobre migración, diversidad y educación, tal como ya se da en aquellos países de Europa y Norteamérica donde el fenómeno migratorio está presente hace varias décadas.

El presente artículo se divide en tres partes. Primero se presenta una descripción de aquello que denominamos aquí "el contexto migratorio actual" de Chile, con especial énfasis en el sistema escolar. En segundo lugar se presenta todo lo relativo al PEIB que en el marco de este artículo se ha decidido observar. Ello contempla una breve revisión al contexto en el cual se originó el PEIB, un análisis de dos de sus características centrales -su grupo objetivo y sus contenidos- y una revisión de las evaluaciones realizadas al programa, seguido por la discusión sobre los eventuales vasos comunicantes de ese programa con el contexto migratorio. En tercer lugar, cerramos la reflexión con las conclusiones que la discusión contenida en este artículo nos deja, respondiendo la pregunta planteada, y proponiendo qué otros elementos podrían significar un aporte en este proceso de complejización de la diversidad en las escuelas.

En términos metodológicos el presente artículo se inscribe en el ámbito de la investigación cualitativa, y siguiendo el planteamiento de Bisquerra Alzina (2009) -quien distingue entre los estudios cualitativos orientados a la comprensión del contexto de estudio y aquellos orientados a la transformación social-, lo cierto es que este artículo tiene elementos tanto de lo primero como de lo segundo: analiza un programa educativo ya existente para aportar a la comprensión de si es pertinente a una realidad relativamente nueva, pero también se propone ofrecer algunas recomendaciones para el cambio en la política educativa, con miras a una educación que considere y valore la diversidad cultural. Como estrategia de recolección y análisis de la información en la elaboración de este artículo se empleó el análisis documental, que ha sido definido como "una actividad sistemática y planificada que consiste en examinar documentos ya escritos que abarcan una amplia gama de modalidades" (Bisquerra Alzina, 2009, p. 349). Dentro del gran espectro de técnicas de recolección de información se puede diferenciar entre técnicas directas o interactivas por un lado, y técnicas indirectas o no interactivas por otro, y el análisis documental es parte de este segundo conjunto de técnicas. Estas "agrupan la lectura de documentos escritos que, por un lado, recogen la evolución histórica y la trayectoria de comportamiento, de funcionamiento y de organización de la realidad, y por el otro, las percepciones escritas [...] sobre esta situación" (Bisquerra Alzina, 2009, p. 331). En el caso de este artículo, los documentos analizados corresponden a escritos de diversa naturaleza, y muchos de ellos fueron construidos sobre la base de entrevistas con los actores directamente involucrados en estos procesos: informes gubernamentales, informes de organismos internacionales $\mathrm{y}$, sobre todo, artículos académicos. Los informes gubernamentales refieren principalmente a publicaciones del Mineduc; las informaciones de organismos internacionales refieren a publicaciones de la Organización de las Naciones Unidas para la Educación, la Ciencia y la Cultura (Unesco), la Organización para la Cooperación y el Desarrollo Económicos (OCDE), y el Centro Latinoamericano y Caribeño de Demografía (Celade). Los artículos académicos refieren a una serie de textos publicados en los últimos 15 años en revistas especializadas que fueron encontrados a través de buscadores en línea, mediante el ingreso de palabras claves tales como migración, pueblos indígenas, educación, Chile, América Latina, interculturalidad y multiculturalidad. 


\section{El contexto migratorio actual y algunos antecedentes sobre la situación de los alumnos migrantes en las escuelas chilenas}

La sostenida inmigración que Chile experimenta actualmente se remonta a los ańos noventa, década que en términos políticos estuvo marcada -al menos nominalmente- por el fin de la dictadura militar, y en términos económicos, por un fuerte crecimiento que se mantuvo durante algunos ańos. A partir del año 2001, Chile comenzó a posicionarse como uno de los principales países de destino de la migración en la región de América del Sur. Esto se debió tanto a los procesos de securitización de fronteras en el primer mundo -a consecuencia de los atentados del 11/S (2001) en Estados Unidoscomo a la profunda crisis económica y política de Argentina, que hasta esa fecha había sido el principal destino migratorio del Cono Sur (Rojas y Silva, 2016, p. 5). Desde el año 2001 se hacen claramente visibles ciertas particularidades de la inmigración, como una fuerte presencia femenina, indígena y, más recientemente, afrodescendiente. Estos flujos migratorios han estado marcados principalmente por motivaciones laborales, pero en algunos casos, de acuerdo a Rojas y Silva (2016) se trata también de "una migración forzada por contextos de origen golpeados por la violencia social y estructural, que busca en Chile cierta estabilidad política y económica que -aparentemente- los países vecinos y los propios países de origen no estarían brindando" (Rojas y Silva, 2016, p. 5).

De acuerdo al censo de población más reciente, en el año 2017 había 746.465 migrantes residiendo en Chile, lo que corresponde al 4,35\% de la población total habitando en Chile. La principal comunidad inmigrante es la de los peruanos $(25,2 \%)$, seguida por la de los colombianos $(14,1 \%)$, venezolanos $(11,1 \%)$, bolivianos $(9,9 \%)$, argentinos $(8,9 \%)$, y haitianos $(8,4 \%)$ (Instituto Nacional de Estadísticas, INE, 2017).

Tal como se mencionó más arriba, en sus comienzos esta migración reciente hacia Chile fue predominantemente femenina, es decir, protagonizada por mujeres que migraban por lo general solas, sin pareja ni familia (Stefoni, 2011; Acosta, 2015).
Sin embargo, en los últimos años se han iniciado procesos de reunificación familiar o migraciones realizadas por grupos familiares completos, lo que ha implicado la llegada creciente de niños, niñas y jóvenes, que se han ido insertando progresivamente en establecimientos educacionales chilenos. Durante el año 2018 el Mineduc ha publicado algunos documentos que entregan información sobre la situación de los estudiantes extranjeros en las escuelas chilenas (Mineduc, 2018a, 2018b), y adicionalmente, un conjunto no menor de investigaciones académicas, informaciones publicadas por organizaciones de la sociedad civil y tesis de pre y posgrado han aportado datos cuantitativos y cualitativos que contribuyen a caracterizar esta situación.

Antes de introducirse en el caso de los alumnos migrantes, es relevante detenerse brevemente en los elementos que hoy caracterizan al sistema escolar chileno.

El sistema escolar actual está fuertemente marcado por las reformas de principios de la década de los ochenta, llevadas a cabo por los equipos económicos de la dictadura militar encabezada por Augusto Pinochet. Las reformas en la educación fueron parte de un paquete más amplio de reformas económicas de corte neoliberal, de una extrema orientación hacia el mercado (Valenzuela, Bellei y De los Ríos, 2013), incluso en la provisión de bienes y servicios que constituyen derechos sociales básicos. Durante la dictadura se configuró un cuasi mercado de la educación (Joiko, 2012; Falabella, 2015), altamente segmentado, que hasta el día de hoy se expresa en la coexistencia de básicamente tres tipos de establecimientos educativos: a) establecimientos públicos, administrados por los gobiernos locales, financiados exclusivamente por un aporte estatal, y a los cuales en el ańo 2017 asistía un 35,8\% del alumnado, b) establecimientos particulares subvencionados, administrados por personas particulares, fundaciones o corporaciones, financiados por el aporte estatal y eventualmente mediante un copago de los apoderados, y que en el 2017 concentraba al 54,6\% del alumnado, y c) establecimientos privados, también administrados por personas particulares, fundaciones o corporaciones, que se financian exclusivamente mediante los aportes provenientes del pago de matrícula y mensualidades por parte de los apoderados, y a 
los cuales el 2017 asistía el 8,3\% del alumnado total en Chile. El restante 1,3\% asistió a establecimientos administrados por corporaciones de administración delegada. ${ }^{4}$

Respecto de la calidad de la educación en Chile, llama la atención que al mismo tiempo que figura en las mediciones internacionales como el país de mejor educación en América Latina (Rivas, 2015), destacando en las pruebas PISA tanto en matemáticas, como en lectura y ciencias (Agencia de Calidad de la Educación, 2015, p. 17), es también el país de peor desempeño en el marco de la OCDE (Sepúlveda, 2016).

Conviene destacar que durante los últimos años se han producido transformaciones muy relevantes que apuntan a desmantelar el sistema educativo heredado de la dictadura. En primer lugar, a comienzos del año 2016 entró en vigencia la así llamada Ley de Inclusión, que entre otros aspectos prohíbe la selección de alumnos por parte de los establecimientos, termina con el copago y prohíbe asimismo el lucro. Antes de la entrada en vigencia de dicha ley, todo lo anterior estaba permitido o se realizaba de facto, sin sanciones de por medio. En segundo lugar, muy recientemente el Parlamento chileno aprobó que la educación pública, que a consecuencia de las reformas neoliberales había quedado bajo la administración de los municipios (gobiernos locales), avance hacia la así llamada desmunicipalización, y vuelva a ser administrada directamente por el Estado. ${ }^{5}$

Con todo, lo cierto es que la permanencia del modelo neoliberal en la educación chilena se expresa en varios aspectos, por lo que los establecimientos se ven enfrentados a una contradictoria agenda de trabajo. Por ejemplo, por una parte se les pide valorar la diversidad social y cultural en sus aulas (como lo indica la nueva ley de inclusión), pero a la vez se les exige responder a mecanismos de rendición de cuentas estandarizados, que no dan cuenta de la

4 Fuente: Unidad de Estadísticas, Centro de Estudios, División de Planificación y Presupuesto, Mineduc. Disponible en http://datosabiertos.mineduc.cl/ (Consultado el 30.09.2018).

5 https://www.publimetro.cl/cl/noticias/2017/10/03/congreso-aprobo-el-proyecto-de-desmunicipalizacion-dela-educacion-publica.html (Consultada el 4.10.2017) diversidad. Este es el caso de las pruebas que se aplican en el marco del Sistema de Medición de la Calidad de la Educación (SIMCE), ${ }^{6}$ que de hecho ha sido objeto de diversos cuestionamientos por parte de profesores, directivos e investigadores en educación. ${ }^{7}$

De acuerdo a información del Mineduc, durante el año 2017 la cantidad de alumnos migrantes llegó a 77.608 (Mineduc, 2018b, p. 7), representando cerca del 2,3\% del total del alumnado en Chile. "Las estadísticas también muestran que la mayor parte de los alumnos extranjeros $(57,5 \%)$ estudia en establecimientos municipales, mientras que un $33,1 \%$ lo hace en particulares subvencionados, un $7,9 \%$ en particulares pagados y un $1,5 \%$ en Centros de Administración Delegada (CAD). La tasa de estudiantes extranjeros en establecimientos municipales aumentó del 1,5\% el ańo 2015 al 3,5\% el 2017, lo cual ha contribuido a la estabilización de la matrícula municipal, pero a su vez ha levantado la necesidad de observar y analizar con mayor profundidad el nuevo contexto de estas comunidades educativas, sobre todo si consideramos [...] que de la totalidad, un tercio se encuentra en situación migratoria irregular y no cuentan con visa ni RUN nacional" (Mineduc, 2018b, p. 7).

Desde la década del dos mil en adelante, varias investigaciones de índole cualitativa han visibilizado qué temas específicos atañen al alumnado migrante al interior del sistema educativo chileno. Uno de los primeros temas que quedó al descubierto es que estos alumnos estaban teniendo problemas de acceso (Stefoni et al., 2008). De hecho, la primera normativa que el Ministerio de Educación dictó sobre este

6 http://www.agenciaeducacion.cl/evaluaciones/que-esel-simce/

7 Para más información, sugerimos por ejemplo revisar la campaña "Alto al Simce", que en el año 2014 era liderada por un académico de la Universidad de Santiago (http://educacion.usach.cl/index.php/404-academicojaime-retamal-lidera-campana-alto-al-simce), la información proporcionada por la Fundación Educación 2020 (http://www.educacion2020.cl/los-6-mitos-delsimce) y el artículo de Román y Corvalán (2016), que describe que para ciertas familias el Simce no es indicador de calidad educativa, y que existe al respecto una distancia entre la mirada de los padres y la conceptualización que emana de la política educativa. 
aspecto data de mediados de la década de los noventa (Mineduc, 1995), lo que permite inferir que ya en esa fecha ese ministerio tenía conocimiento de que algunos establecimientos educativos estaban negando a ciertos nińos o jóvenes migrantes la posibilidad de matricularse. La dictación de varias normas nuevas $^{8}$ a lo largo de los años sugiere que las dificultades en el acceso no se han resuelto del todo, pero se ha ido avanzando en la materia, y en la actualidad ese ya no parece ser un problema central. ${ }^{9}$ Es relevante comentar que existen algunos establecimientos con una fuerte concentración de alumnado migrante, mientras que otros, de las mismas comunas, tienen una proporción baja de este tipo de alumnos. Probablemente esta situación haya comenzado a configurarse debido a la inicial negativa de algunos establecimientos a recibir alumnos migrantes -junto a factores como la segregación territorial y la fortaleza de las cadenas migratorias (Donoso, Mardones y Contreras, 2009, p. 57)-, mientras que en paralelo otros establecimientos, conocidos como "de puertas abiertas", estuvieron especialmente bien dispuestos a recibir alumnos migrantes (Molina, 2015; Joiko y Vásquez, 2016). ${ }^{10}$

8 Por ejemplo, en 2003, y mediante la Circular 1179 del Ministerio del Interior, se puso en marcha la campańa "Por el derecho a la educación", orientada a facilitar y promover la incorporación de los hijos de inmigrantes que residían en Chile a los diversos establecimientos de la educación general básica. En marzo del mismo año, mediante el Oficio Circular 6232 del Ministerio del Interior, se precisó el sentido y alcance de la circular anterior, enfatizando que el otorgamiento de ese permiso de residencia debía ser independiente de la condición “irregular" del menor (Stang, 2016, p. 9).

9 De todos modos, es relevante mencionar que estadísticas recientes alertan sobre una menor tasa de asistencia de niños y niñas migrantes tanto en el nivel básico (85,8\% para la población inmigrante frente al $91,6 \%$ para la población nacida en Chile) como en el nivel medio $(66,8 \%$ para la población inmigrante frente al $73,8 \%$ para la nacida en Chile) (Subsecretaría de Evaluación Social, 2016). Estas cifras dan cuenta de que pese a las estrategias implementadas, tendientes a garantizar el acceso al sistema escolar de todas y todos los niños inmigrantes, subsiste un porcentaje que se encuentra excluido del sistema escolar nacional.

10 Uno de los elementos que ha contribuido a la buena disposición de ciertas escuelas y liceos a recibir alumnos migrantes se relaciona con el hecho, tal como fue expuesto más arriba, de que había comenzado a darse una "fuga" de alumnos (chilenos) que se cambiaban a
Una razón por la cual la concentración representa una situación compleja se debe al hecho de que "el sistema educativo chileno reproduce las desigualdades existentes en los otros ámbitos de la sociedad" [...] existe "una desigual distribución de estudiantes, donde se aglomeran los/as de peores resultados escolares en los establecimientos municipales y en menor medida en los subvencionados pagados, y los mejores en los particulares subvencionados" (Mardones, 2006, pp. 5-6).

En el marco de esta realidad que se ha configurado, son especialmente relevantes tres temas que están presentes en los establecimientos educativos que cuentan con alumnado migrante: la existencia de una normativa que en la práctica produce que existan alumnos "de primera clase" y otros "de segunda clase", la vivencia de situaciones de discriminación racista por parte de los alumnos migrantes, y la falta de herramientas específicas del profesorado para trabajar con un alumnado culturalmente diverso.

En virtud de los problemas de acceso que el Ministerio de Educación había comenzado a observar en los ańos noventa, y que a inicios de la década del dos mil aún eran evidentes, en agosto de 2005 el Oficio ordinario 07/1008-1531 apuntó a asegurar el ingreso, la permanencia y el ejercicio de los derechos de los alumnos inmigrantes en los establecimientos educacionales, con independencia del estatus migratorio del menor y de sus padres. Para tal efecto creó

la educación particular subvencionada, poniendo en riesgo la continuidad de algunos establecimientos municipales. Aún no existe un consenso definitivo acerca de las razones que han producido esa fuga, pero muchos indicios apuntan a que las familias que tienen la posibilidad de pagar por la colegiatura prefieren hacerlo, y esto se debería a razones asociadas al prestigio. Las mediciones de logro educacional han mostrado consistentemente que los colegios particulares subvencionados no alcanzan mejores puntajes que los colegios municipales en las pruebas estandarizadas, pero esa evidencia no parece haber sido de relevancia para las familias que han apoyado el traslado de sus hijos de un establecimiento gratuito a otro pagado. Como también fue mencionado, solo a inicios del año 2017 entró en vigencia una ley nueva al respecto. Permite la permanencia de la figura de los colegios particulares subvencionados, pero prohíbe la selección, el copago y el lucro en todos los establecimientos que reciben fondos públicos (Mineduc, 2017a). 
la figura de la matrícula provisoria, previa autorización del respectivo Departamento Provincial de Educación y la presentación de un documento que acreditara su identidad y edad (Stang, 2016, p. 10). Esta matrícula provisoria contribuyó a facilitar el acceso expedito, pero también incidió en que se configurara una situación con dos tipos de alumnos: unos con RUT $^{11}$ definitivo, otros con RUT provisorio ${ }^{12}$ o "RUT 100": estos alumnos llegaron a ser denominados informalmente como "estudiantes fantasma" debido a la imposibilidad de ser registrados en el sistema de información general de educación (SIGE) (Arias, 2016; Correa, 2016; Palma y Joiko, 2016). En enero de 2017 entró en vigencia un instrumento nuevo (Subsecretaría de Educación, 2016) que reemplaza a la matrícula provisoria y que lleva el nombre de Identificador Provisorio Educacional (IPE); uno de sus objetivos fue garantizar el ejercicio efectivo de derechos de los alumnos migrantes (Joiko y Vásquez, 2017, p. 6). Sin embargo, datos recientes indican que aún persisten problemas, como por ejemplo en la inscripción de los alumnos migrantes en la prueba para ingresar a la universidad. ${ }^{13} \mathrm{La}$ inequidad en los derechos de los alumnos está directamente vinculada a que la normativa migratoria de Chile, más allá de lo educativo, tiene más de 40 ańos de antigüedad, y se encuentra por tanto completamente desactualizada: no garantiza ningún tipo de derecho y está más orientada a obstaculizar que a regular el ingreso de extranjeros a Chile. Esto evidentemente tiene efectos también sobre los derechos de los niños y jóvenes migrantes.

11 La sigla RUT se refiere al "Rol Único Tributario" y corresponde en Chile al número que identifica a cada persona frente a la institucionalidad. Para las personas nacidas en Chile, este número identificador es asignado en el mismo momento de la inscripción del nacimiento ante el Registro Civil.

12 Frente a la realidad de los alumnos con RUT provisorio, en 2014 el Ministerio del Interior puso en marcha el programa "La Escuela Somos Todos", que a través de la firma de convenios entre municipios determinados y el Departamento de Extranjería y Migración propone la promoción de la regularización de los estudiantes extranjeros y sus familias a partir de la escuela (Stang, 2016, p. 10).

13 En julio de 2017 la presidenta Bachelet anunció la creación de una visa nueva para alumnos migrantes. Hasta la fecha de publicación de este artículo no se había dictado el reglamento correspondiente, por lo que esta nueva norma aún no entra en vigencia.
La vivencia de situaciones de discriminación racista por parte de los alumnos migrantes se encuentra, a estas alturas, ampliamente documentada por una serie de investigaciones realizadas en los últimos años en establecimientos de diferentes zonas de Chile (Pavez, 2012; Tijoux, 2013a; Marín, 2014; Riedemann y Stefoni, 2015; Beniscelli, 2016; Correa Téllez, 2016; Stefoni, Stang y Riedemann, 2016). "La discriminación en la escuela se ha vuelto tan cotidiana, que los nińos y niñas inmigrantes la han naturalizado, y han internalizado estas dificultades como parte de los costos de la migración y sus familias" (Corporación Colectivo Sin Fronteras, 2007, pp. 140-141, citado en Jiménez et al., 2017, p. 110). A una conclusión similar llega un artículo enfocado específicamente en la inmigración peruana, que plantea que "los niños(as) deben soportar el racismo, como un 'modo de ser' de los chilenos" (Tijoux, 2013b, p. 99). Sin embargo, es evidente que no por haberse vuelto un tema cotidiano, el racismo deja de representar una vulneración grave de derechos, que produce sufrimientos y deja huellas profundas en quienes lo experimentan.

Evidentemente, la discriminación racista no está presente solo en los establecimientos educativos, sino en la sociedad chilena en general. Nos aventuramos a afirmar que en Chile este tipo de discriminación se encuentra relativamente validado y que esta situación se deriva de su pasado colonial y de las dinámicas de conformación de la identidad nacional chilena. A partir de ellas se dieron procesos "de producción e inscripción en los cuerpos de marcas o estigmas sociales de carácter racial [...] en que determinados rasgos corporalizados son considerados jerárquicamente inferiores" (Tijoux y Palominos, 2015 , p. 250). Hasta la fecha, la oferta de formación docente con enfoque intercultural en Chile es muy acotada (y se refiere exclusivamente a poblaciones indígenas), lo que implica una importante carencia, ya que habilitaría a los profesores a reconocer ciertas prácticas como racistas y a intervenir adecuadamente cuando estas fueran observadas (Riedemann y Stefoni, 2015, pp. 206-212). De todos modos, no es solo en relación al racismo, sino también a varios otros temas consustanciales de la diversidad que la formación docente necesita actualizarse (Sánchez, Navas y Holgado, 2013). Algunos profesores le restan importancia a la diversidad cultural 
del alumnado y ponen en su lugar otras variables, como la condición de vulnerabilidad del alumnado o la pertenencia a determinadas clases socioeconómicas. "La falta de sensibilidad del profesorado a la necesidad de un replanteamiento global de la lógica educativa en contextos de diversidad cultural, les impide tomar conciencia de cómo algunas diferencias culturales se podrían traducir en barreras para el aprendizaje y la participación, constituyéndose en elementos desencadenantes de la desigualdad educativa” (Jiménez y Fardella, 2015, pp. 428-429). De modo complementario a lo anterior, resulta interesante plantear también que la situación de los alumnos migrantes no es un tema de reflexión para los docentes, y que esto es justificado a través de la aparente adaptación de esos estudiantes al sistema educativo local (Bustos y Gairín, 2017, p. 204). Un elemento coadyuvante a que la práctica de los profesores en Chile hasta la fecha solo escasamente haya incorporado un enfoque intercultural es el hecho de que también el currículum chileno tiene pendiente una actualización en este sentido (Poblete, 2009; Johnson, 2015). La ausencia del enfoque intercultural implica, en la práctica, que el currículum no está sirviendo como guía a aquellos profesores que tienen interés en incorporar dicho enfoque en sus procesos de enseńanza-aprendizaje.

De manera paralela a las demandas que han estado emergiendo por una formación docente con enfoque intercultural, es interesante consignar que una serie de colectivos, tanto académicos como de la sociedad civil y a nivel de gobiernos locales, han comenzado a implementar iniciativas para hacer frente a la tensión que la diversidad de nacionalidades, lenguas y colores de piel ha producido en escuelas, colegios y liceos. ${ }^{14}$

14 Por ejemplo, las iniciativas y publicaciones del Colectivo Sin Fronteras (www.sinfronteraschile.cl), la iniciativa "Contra el racismo nos educamos", que surgió en la escuela de Sociología de la Universidad de Chile, (http://radio.uchile.cl/tag/contra-el-racismo-nos-educamos), el proyecto "Chita Pale, sentarse a conversar" del Colectivo Trama (www.revistasur.cl/revistasur. cl/2016/10/encuentro-creativo-chita-pale-se-abre-unmapa-de-conversacion), los talleres ofrecidos durante el año 2016 por el Colectivo Mesa por una Educación Intercultural (www.facebook.com/educacioninterculturalchile), la creación del Observatorio Chileno de Inclusión Educativa Migrante (www.migracionyedu-
La existencia de jerarquías (representadas por ejemplo por el RUT chileno versus otros registros provisorios) de discriminación, y la ausencia de una formación del profesorado para la diversidad, dan cuenta de un sistema educacional marcado por una discriminación estructural, que necesita ser revisado desde sus bases. Por ello reafirmamos que el enfoque de la interculturalidad crítica es necesario en el abordaje de esta cuestión, tanto en Chile como en América Latina en general.

\section{Características de la educación intercultural bilingüe en América Latina y en Chile, y sus eventuales vasos comunicantes con el contexto migratorio}

A pesar de que actualmente la educación intercultural bilingüe en Chile tiene elementos en común con la de otros países de América Latina, existen en su genealogía ciertas diferencias y particularidades que resultan importantes de mencionar. En varios países de América Latina, y especialmente en aquellos donde el porcentaje de la población indígena sobre la población total históricamente ha sido muy alto, desde los inicios del siglo XX se usaron las lenguas indígenas como herramienta para lograr una pronta asimilación de las poblaciones indígenas a la lengua y cultura hegemónica (López y Küper, 2002). Aunque las primeras experiencias de bilingüismo no fueron expresión de un respeto por la diversidad sino más bien de un afán nacionalista y asimilacionista, de todas formas es relevante destacar que estas tempranas experiencias de educación bilingüe fueron un antecedente de lo que más tarde llegaría a ser, en esos países, la educación intercultural bilingüe.

Un impulso relevante a las mencionadas experiencias tempranas de bilingüismo provino del movimiento

cacion.cl), la elaboración de la "Guía Pedagógica por una educación intercultural, anti-racista y con perspectiva de género" de PRIEM y FUSUPO (http://www. superacionpobreza.cl/wp-content/uploads/2017/03/ Gu\%C3\%ADa-pedag\%C3\%B3gica-para-unaeducaci $\% \mathrm{C} 3 \% \mathrm{~B} 3 \mathrm{n}$-intercultural-anti-racista-y-conperspectiva-de-g\%C3\%A9nero.pdf), la elaboración del manual "La infancia mundial en la escuela aumenta el capital cultural" (www.academia.edu/31089720/Manual_la_infancia_mundial_en_la_escuela_aumenta_ el_capital_cultural), entre otros. 
indigenista. En parte surgido como respuesta ante la creciente influencia material y cultural de los Estados Unidos en América Latina, y la consiguiente búsqueda y revalorización de las culturas propias del continente latinoamericano, el indigenista fue un movimiento cultural que comenzó a desarrollarse desde la década del veinte, especialmente en países como Perú y México. Este movimiento, que partió siendo un sentimiento proclive a los pueblos y culturas indígenas, derivó posteriormente en la creación del Instituto Indigenista Interamericano (I.I.I.), cuya misión fue impulsar "la política que realizan los estados americanos para atender y resolver los problemas que confrontan las poblaciones indígenas, con el objeto de integrarlas a la nacionalidad correspondiente" (Marroquín, 1977, p. 13).

A pesar de que el gobierno chileno envió a un representante a la ceremonia de fundación del I.I.I., realizada en 1940 en la ciudad de Pátzcuaro, México, es posible aventurar que la participación de Chile en el movimiento indigenista se limitó a los aspectos más bien formales. Existen antecedentes para pensar que la participación chilena en dicha convención -representada por Venancio Coñuepán, líder de una importante organización mapuche (Bengoa, 1999, pp. 95-115) - no era expresión de un verdadero interés en el bienestar de la población indígena, sino que buscaba aprovechar el vínculo que se había instalado discursivamente entre el indigenismo y la retórica nacionalista dominante en ese tiempo (Rinke, 2002). Como ejemplo, valga el hecho de que mientras 14 países latinoamericanos ratificaron el I.I.I. en los seis años siguientes de su fundación (es decir, entre 1940 y 1946), Chile recién lo ratificó en el año 1968 (Marroquín, 1977, p. 61). Además, nunca creó un Instituto Nacional Indigenista, como sugería la Convención de 1940. Un segundo aspecto relevante es que la Dirección de Asuntos Indígenas (DASIN), creada en 1953 y que quedó a cargo de Cońuepán, contó con un presupuesto tan limitado y con atribuciones tan poco claras, que pudo concretar muy poco de lo que por mandato le correspondía realizar. En la memoria de la DASIN para el año 1956, su director finalizó su informe diciendo textualmente: "Como lo hemos estado representando en cada ocasión, sin dinero y sin personal suficiente, nada o muy poco se ha podido realizar" (Coñuepán y Lemunguier, s.f., p. 13).
Lo anterior hace pensar que existió la intención gubernamental por aparentar un compromiso con una política indigenista, pero no una verdadera voluntad política por llevarla a cabo. A pesar de las constantes demandas de diferentes colectivos indígenas por una educación diferenciada y pertinente, la educación chilena durante la mayor parte del siglo XX fue centralizada y homogeneizante, y no implementó ningún tipo de transformación curricular derivada de la diversidad cultural que, en la práctica, ha existido en el país al menos desde la conformación del Estado nacional en adelante. En definitiva, antes de la década del noventa no se encuentran en Chile antecedentes concretos que más adelante se expresaran en el diseño del PEIB.

En Chile, el programa que hasta el día de hoy lleva el nombre de educación intercultural bilingüe surgió de la mano de una ley promulgada pocos años después del traspaso de mando de Augusto Pinochet a Patricio Aylwin, ocurrido en marzo de 1990. La así llamada Ley Indígena, que entró en vigencia en 1993, entre otros aspectos indicaba lo siguiente: "La Corporación (de Desarrollo Indígena, o Conadi), en las áreas de alta densidad indígena y en coordinación con los servicios u organismos del Estado que correspondan, desarrollará un sistema de educación intercultural bilingüe a fin de preparar a los educandos indígenas para desenvolverse en forma adecuada tanto en su sociedad de origen como en la sociedad global" (Gobierno de Chile, 1993, Ley 19.253, art. 32). La Ley Indígena, y en consecuencia también el PEIB, fueron resultado de una negociación política que se había iniciado con el así llamado Acuerdo de Nueva Imperial (Williamson, 2012, p. 140), entre la coalición "Concertación de Partidos por la Democracia" y miembros de los pueblos indígenas. Con ese origen, en 1996 se inició el primer programa piloto de educación intercultural bilingüe implementado por el Estado chileno.

La década del noventa en Chile tuvo la particularidad de estar marcada, en términos económicos, por la instalación y profundización del modelo neoliberal en muchos de los ámbitos de la sociedad. La relación del Estado con las etnias ${ }^{15}$ indígenas reconocidas en

15 Usamos aquí el concepto etnia exclusivamente porque ese es el concepto que contiene la Ley Indígena. El 
la Ley Indígena fue uno de ellos, y el concepto del multiculturalismo neoliberal describe bien dicha situación: propuesto entre otros autores por Hale (2002), plantea examinar críticamente el efecto que las reformas pro indígenas han tenido en América Latina a partir de los años noventa (Hale, 2002), y en relación al caso específico del Chile de la posdictadura, Boccara y Ayala (2011) plantean que el multiculturalismo puede ser definido como un nuevo arte de gobierno de la diferencia -o etnogubernamentalidad- que se articula de varias maneras con el neoliberalismo (Boccara y Ayala, 2011). De este modo, en las relaciones sociales que comenzaron a configurarse desde esa época, al racismo estructural de la sociedad chilena -heredado del colonialismo y el nacionalismo- se le sumó la interacción del neoliberalismo, con su mirada y acción utilitarista y pragmática sobre prácticamente todos los aspectos de la vida en sociedad.

En ese marco, a partir del ańo 2000 el PEIB se comenzó a institucionalizar y se agrega un nuevo componente denominado Orígenes ${ }^{16}$ (programa gubernamental financiado por el Banco Interamericano del Desarrollo, BID, dirigido a mejorar la calidad de vida de las comunidades indígenas rurales), que apuntó a reforzar el objetivo del PEIB. Posteriormente, a través del Decreto con Fuerza de Ley (DFL) No 1 de 2005, se crea como parte de la política educativa el Sector de Lengua Indígena (Williamson, 2012, p. 137), cuya formalización se sustenta legalmente en el Decreto 280 emanado

Estado chileno ha reconocido la existencia de etnias, pero no de pueblos indígenas, como sugiere el derecho internacional.

16 El propósito del Programa Orígenes fue promover el desarrollo con identidad de comunidades rurales indígenas en siete regiones del país, fortaleciendo sus capacidades y generando mayores oportunidades en su entorno público. El convenio entre el Gobierno de Chile y el BID conceptualizó el Programa Orígenes en dos fases: una primera fase ejecutada entre los años 2001 y 2006, caracterizada como una experiencia piloto en la que se implementaron de manera experimental metodologías y modelos, y una segunda en que se ajusta el programa en función de los aprendizajes. La segunda fase se inició en enero de 2007, y contempló una duración de cinco años, hasta el 2011 (Fuente: http:// www.conadi.gob.cl/index.php/noticias-conadi/20-programa-origenes/259-programa-origenes). del Ministerio de Educación en el año 2009. En el año 2010, el Mineduc incorpora la nueva asignatura "Lengua y Cultura Indígena" dentro del currículo nacional (DAEM Temuco, 2016, p. 10). Además de la creación de dicha asignatura, el PEIB ha impulsado en estos últimos años iniciativas tales como proyectos de mejoramientos educativos e institucionales en EIB, incorporación de educadores tradicionales para la promoción lingüística y cultural, contextualización de planes y programas de estudio, capacitación docente continua, becas, y apoyo a carreras universitarias en EIB (Abarca, 2015, p. 3).

Los objetivos y el funcionamiento del PEIB han sido objeto de múltiples debates y reflexiones, incluidas algunas evaluaciones. La primera evaluación institucional que se realizó al PEIB fue parte de la evaluación al sistema educacional chileno llevada a cabo por la OCDE en 2003. Esta reconoció y valoró la EIB, pero también indicaba "la inexistencia de una política pública coherente, dada su incorporación tardía a la reforma educacional" (citada en Williamson, 2012, p. 143). En el año 2004 se publicó el informe final de la evaluación al programa Orígenes, que observa la presencia de dos lógicas contrapuestas en el PEIB: "La primera pone énfasis en el fortalecimiento de las tradiciones culturales de las comunidades indígenas, mientras que la segunda pone énfasis en el mejoramiento a partir de resultados..." (Le Bert, Winchester y Caro, 2004, p. 23). En el mismo año un estudio del Departamento de Antropología de la Universidad de Chile evaluó la eficiencia y pertinencia del PEIB en escuelas de la región Metropolitana. Respecto de la eficiencia, el estudio destaca varios aspectos que muestran falencias, como por ejemplo que la cobertura del programa sea menor al 5\%, que haya una gran discontinuidad en el programa, se trate de experiencias aisladas, y que no han logrado un impacto en el currículum. Por otra parte, respecto de la pertinencia, la evaluación indica que el programa promueve una educación ahistórica, parcializada, estática, esencialista y descontextualizada (Hernández, 2004, pp. 86-87). Los autores concluyen que a través de este programa se le niega a la educación intercultural su potencialidad catalizadora de transformaciones sociales y económicas (Ibíd., pp. 88-90). 
En 2005, un artículo basado en la observación de clases en 138 de las 162 escuelas beneficiarias del programa Orígenes concluye que "en más del 60\% de los casos, la cultura indígena es irrelevante dentro del currículo escolar" (Hevia e Hirmas, 2005, p. 7). Además, se plantea que "la comprensión de la interculturalidad acotada a lo indígena [...] implica que no se está aportando a la discusión sobre la construcción de relaciones interculturales de cooperación” (Ibíd, p. 11). Esto coincide con la apreciación de otro trabajo sobre el PEIB, que plantea que al enfocar esta política exclusivamente en nińos de ascendencia indígena, el programa se autoimpone una traba en su objetivo, que finalmente es el de mejorar la calidad de vida de dichos nińos (Riedemann, 2008). Lo anterior es corroborado por un estudio realizado en relación al pueblo mapuche, que -aun cuando no hace referencia exclusivamente al PEIBconcluye que el impacto de la educación en la movilidad social es más bajo para los mapuche que para los mestizos y los no mapuche (Williamson y Cantero 2010, citado en Williamson, 2012, p. 129).

A partir de 2008 se llevó a cabo un estudio con el fin de "tener evidencia sobre cómo los establecimientos estaban implementando esta política educativa, cuáles eran los nudos críticos y de qué modo estaban surgiendo avances respecto del objetivo principal del Programa" (CIAE, 2011, p. 3). ${ }^{17}$ Los autores del estudio evitan definirlo como una evaluación, pero plantean que se trata de "una aproximación de los aspectos positivos que se observan en terreno, como también de las carencias que se deberán enfrentar en pro de un mejoramiento cualitativo de la educación intercultural en el país" (CIAE, 2011, p. 96). Consignan asimismo que a la fecha de realización de su estudio no existía ninguna evaluación formal realizada previamente que pudiera servir de orientación (Ibíd., p. 11), lo que a nuestro juicio confirma, una vez más, que el valor simbólico de las políticas dirigidas a población indígena han sido más relevantes que su valor concreto, en el sentido de abocarse a cumplir con eficiencia aquel objetivo que dice perseguir. Los aspectos positivos que releva el estudio de

17 "Mejorar la calidad y pertinencia de los aprendizajes a partir de la contextualización curricular y fortalecimiento de la identidad étnica de niños, niñas, jóvenes y adultos" (CIAE, 2011, p. 3).
CIAE "se relacionan a la creciente valoración que los docentes manifiestan por la enseńanza intercultural, lo que va en consonancia con la práctica de acciones culturales relativas a la identidad étnica" (Ibíd., p. 96). Sin embargo, frente a este aspecto positivo más bien acotado, existe un extenso listado de críticas: una casi nula definición de las nociones utilizadas -tales como identidad, cultura, interculturalidad, bilingüismo-, el concebir a los pueblos originarios fundamentalmente como carentes, sin capacidad propositiva, el no tomar en cuenta otros agentes educativos como familia y comunidad, y que la interculturalidad no sea entendida como enfoque educativo, sino que como educación indígena (Fernández, 2005, citado en CIAE, 2011, pp. 96-97).

Un estudio más reciente, realizado en una fecha en que el PEIB ya había explicitado su foco en lengua y cultura, sostiene que "en todas las experiencias revisadas, sus resultados, su calidad y su nivel de profundización dependen directamente del esfuerzo individual de los profesores encargados y, en menor medida, del equipo de dirección del establecimiento" (Lagos, 2015, p. 88). Específicamente en relación al tema de la lengua, se plantea que los estudios enfocados en evaluar este aspecto dan cuenta de una serie de problemas que se suscitan en la práctica. Respecto de la difícil labor del educador tradicional, el autor de este estudio comenta que "al ser una figura de autoridad extraída de su contexto natural de legitimación (la comunidad) y ser trasladado a un escenario artificial de enseñanza (la escuela), el educador tradicional pierde todos sus atributos naturales y queda reducido a un personaje secundario, al no poseer las claves para ser considerado autoridad: no ha estudiado en la educación formal ni pedagogía ni lingüística y no habla un español estándar (sino uno plagado de interferencias del chedungun), lo que suscita incluso burlas de parte de los alumnos hacia su persona" (Lagos, 2015, p. 90). Todo lo anterior lleva al autor a concluir que el PEIB no es una herramienta de revitalización de las lenguas indígenas, y que tampoco cumple con su promesa de ser bilingüe o intercultural.

A las evaluaciones formales y los estudios mencionados se suma otro elemento que puede ser leído como una crítica al diseño y la ejecución actual del PEIB: en ańos recientes al menos una comunidad indígena 
en Chile desarrolló un programa educativo propio para su escuela, ${ }^{18}$ lo que ha sido destacado como una experiencia de pedagogía decolonial (Huenchullán Arrué, 2017). El inicio de la administración de esta escuela por parte de la propia comunidad se inscribe en un proceso más amplio de la historia reciente, en el que se ha ido generando "en las comunidades mapuche y sus líderes un proceso de alzamiento denominado control territorial, que no solo reivindica las hectáreas enajenadas que fueron entregadas a colonos nacionales y extranjeros y que están insertas en el espacio territorial lafquenche, sino que, por sobre todo, el control político de ese espacio. Es también el caso de los mapuche del Budi, quienes se organizaron a través de la alianza territorial mapuche y comenzaron a generar una serie de revueltas y resistencias al proyecto hegemónico [...] la apuesta de la comunidad lafquenche Llaguepulli fue administrar directamente la escuela Kom $\mathrm{Pu}$ Lof Ni Kimeltuwe, con el fin de constituir un lugar de enseńanza para todas las comunidades, conforme a los valores mapuche que a su juicio se estaban descontextualizando por parte de su anterior administrador, es decir, la Iglesia católica (Huenchullán Arrué, 2017, pp. 84-85). La elaboración del nuevo programa educativo de esta escuela no solo se llevó a cabo de manera independiente del PEIB, sino que además se distancia con vehemencia del concepto de interculturalidad propuesto por la política estatal. En la introducción del documento donde ha quedado plasmado este programa educativo, los autores plantean que "Este trabajo de diseño curricular [...] se inicia con la opción política adoptada por las autoridades de la Comunidad Mapuce Bafkehce ${ }^{19}$ de Llaguepulli para elaborar una propuesta educativa afirmando la cultura consuetudinaria mapuce y rechazando cualquier intento de interculturalidad..." (R. Pinto et al., 2011, p. 2).

18 Se trata de la escuela "Kom pu Lof Ñi Kimeltuwe", emplazada en una comunidad mapuche cercana al lago Budi (región de La Araucanía), y que era, al menos hasta el año 2015, el único recinto educacional administrado por una comunidad indígena en Chile (Cayuqueo, 2015).

19 Nota: en esta alusión a los mapuche lafkenche o lafquenche los autores utilizan el grafemario de Anselmo Ranguileo. Agradecemos esta aclaración a Cristián Vargas Paillahueque, integrante del equipo de profesores de mapudungun del colectivo "Kom kim mapudunguaiń waria mew".
La iniciativa de esta escuela corresponde a una opción que en términos formales se encuentra garantizada gracias a la suscripción de Chile al convenio 169 de la Organización Internacional del Trabajo (OIT). En el preámbulo, se plantea que el convenio se justifica, "reconociendo las aspiraciones de esos pueblos a asumir el control de sus propias instituciones y formas de vida y de su desarrollo económico, y a mantener y fortalecer sus identidades, lenguas y religiones, dentro del marco de los estados en que viven" (Preámbulo del Convenio 169, citado en Meza-Lopehandía, 2013, p. 359). El derecho al autogobierno es, en efecto, uno de los derechos colectivos de los pueblos indígenas que en las últimas décadas el derecho internacional ha comenzando a reconocer (Kymlicka, 1996, pp. 46-55). A pesar de que Chile suscribió el convenio 169 de la OIT en el año 2009, el respeto pleno de los derechos allí reconocidos aún no se ha hecho efectivo en la práctica.

\section{Sobre el grupo objetivo de la educación intercultural}

En línea con lo que dictaba la Ley Indígena, el PEIB comenzó implementándose en aquellas escuelas donde los alumnos de ascendencia indígena eran mayoría. Aunque hoy es sabido que la mayor parte de la población indígena de Chile vive en ciudades, en su momento el PEIB fue concebido como un programa a ser aplicado principalmente en el ámbito rural. La explicación de que desde sus inicios el programa fuera concebido como un beneficio exclusivo para niños indígenas radica en que el Estado chileno -al menos en su configuración de inicios de los ańos noventa- quiso dar a entender que reconocía tener una deuda pendiente con los pueblos indígenas del país. ${ }^{20}$ Explicar en detalle el origen de esa deuda excedería los límites del presente artículo, pero se origina, primero, en el reconocimiento de que los pueblos indígenas fueron los primeros ocupantes del territorio que posteriormente fue declarado como chileno (Bengoa, 2004) -de hecho, el término anglosajón para referir a los pueblos originarios, first nations (Battiste y Barman, 1995;

20 La Ley Indígena 19.253 reconoció la existencia de nueve etnias indígenas en territorio chileno: aymara, lickanantai, quechua, colla, diaguita, mapuche, rapanui, kawésqar y yámana. 
Aikenhead, 1997), es elocuente al respecto-; segundo, en que esta ocupación ancestral le confiere a los pueblos indígenas ciertos derechos sobre el territorio que han habitado (Aylwin, 2013, p. 29), y tercero, en el reconocimiento de que el Estado-nacional chileno posteriormente desconoció esos derechos (J. Pinto, 2003, pp. 109-113). Ello llevó a procesos de ocupación, despojo, reasentamientos forzados, fracturas en los modos tradicionales de vivir y empobrecimiento de las comunidades indígenas, por nombrar solo algunos aspectos. A eso se ha sumado un trato injusto ante el sistema judicial, la prohibición de la lengua, la denostación de la cultura y una discriminación de tipo racista, entre muchos otros aspectos. Ante la deuda contraída por el Estado, el foco exclusivo del PEIB en niños de ascendencia indígena fue un intento de ofrecer reparación. ${ }^{21}$

Al poner el foco en la pregunta sobre los vasos comunicantes del PEIB con la realidad migratoria, dada la elección que el PEIB ha hecho respecto de su grupo objetivo -los niños indígenas-, lo lógico sería que una educación intercultural pertinente al contexto migratorio se enfocara exclusivamente en los niños migrantes e hijos de migrantes..$^{22}$ Diversos estudios han detectado que a dichos niños les afectan un cúmulo de necesidades particulares (temas relacionados con visas, otras lenguas, separaciones y reunificaciones familiares, ciertas experiencias de discriminación), por lo que un esfuerzo por resolverlas en efecto representaría una importante contribución al bienestar de esos nińos. Sin embargo,

21 En palabras de Hevia e Hirmas, "la EIB es una forma de saldar, al menos parcialmente, la 'deuda histórica', fruto de la colonización, el ultraje y la marginación de sus pueblos" (Hevia e Hirmas, 2005, p. 14).

22 Existe una discusión mayor que debería darse en torno a la comparabilidad entre un niño indígena y un niño migrante, que sin embargo sobrepasaría los límites del presente artículo. Brevemente, esa discusión refiere a que la condición indígena podría considerarse como algo hereditario (un niño es indígena si uno o ambos padres lo son), mientras que la condición de migrante en estricto rigor solo se adquiere al traspasar, física y materialmente, una frontera (en este caso, una frontera territorial que marca los límites entre un Estado y otro). Queda abierta entonces la pregunta de si un niño hijo de migrantes es, él también, migrante (aunque no haya él mismo participado en la migración, sino que es un niño nacido en el país de destino de la migración de sus padres). replicar una política educacional con pretensiones de interculturalidad que se enfoca exclusivamente en un grupo de alumnos -aquellos que son considerados culturalmente diferentes- tiene implicancias difíciles de sostener: se desconocería una de las grandes críticas formuladas hacia el PEIB, en el sentido de suponer que se puede avanzar verdaderamente en la interculturalidad sin considerar en ello al alumnado completo del sistema educativo. El aporte conceptual de la interculturalidad crítica, esbozado más arriba, contribuye a entender por qué un programa enfocado exclusivamente en un grupo de alumnos no puede, por sí mismo, transformar las estructuras y las relaciones coloniales-raciales que imperan en América Latina. Quienes realmente necesitan aprender de interculturalidad son los miembros de la sociedad mayoritaria, y no (exclusivamente) aquellos que pertenecen a los colectivos que han sido históricamente condenados a ocupar el lugar de las minorías. Aunque un eventual foco exclusivo en los nińos migrantes fuera propuesto como un beneficio al que dichos niños accedieran en virtud de las problemáticas particulares que se asocian a la migración, esta decisión de discriminación positiva desconocería lo que la literatura especializada sugiere respecto a esta temática: es adecuado implementar ciertas estrategias particularistas, compensatorias o de discriminación positiva (Huddleston, Niessen, Ni Chaoimh y White, 2011, p. 16), pero es necesario combinarlas con estrategias de corte universalista, o que se aplican a todos los alumnos por igual.

En el marco de las reformas que se han venido haciendo al sistema educativo chileno y el énfasis en temas como la inclusión, la formación ciudadana y la convivencia, hoy tenemos la posibilidad de avanzar finalmente hacia una educación intercultural para todos. Es el alumnado completo el que debe aprender a cuestionar: los supuestos sobre los que se ha construido la idea de identidad nacional chilena, la historia nacional que hemos aprendido, la idea de que Chile es un país con más influencias europeas que americanas, entre muchos otros aspectos.

\section{Sobre los contenidos de la educación intercultural}

Los objetivos del PEIB transitaron desde su formulación original de preparar a los educandos indígenas tanto para su sociedad de origen como para la 
sociedad global (año 1993), hacia la formulación de "contribuir a los logros de aprendizaje a partir del fortalecimiento de la identidad étnica" (año 2005). En su origen, el PEIB fue un programa de "educación compensatoria para indígenas, tendiente a mejorar su rendimiento y su posibilidad de ascenso social” (Lagos, 2015, p. 86), pero no se especificó a través de qué contenidos se esperaba alcanzar los objetivos del programa. En los últimos ańos, no obstante, se ha explicitado que los focos de aprendizaje del PEIB se encuentran en los ámbitos de la lengua y la cultura. ${ }^{23}$

Si el PEIB, tal como lo sugiere el estudio del CIAE (2011, p. 107), fuera claro en plantear que no responde realmente a la noción de interculturalidad sino que es un programa de educación indígena o de revitalización lingüística, sería entendible que los contenidos estuvieran enfocados en lengua y cultura. Pero el hecho de que el nombre de este programa contenga el vocablo "intercultural" en su título, abre otro flanco de críticas. La interculturalidad apunta a mucho más que la valoración o la revitalización de una lengua o cultura. Desde la perspectiva de la interculturalidad crítica, resulta evidente que el foco en esos contenidos no responde de manera suficiente a lo que el concepto de interculturalidad implica. Por lo tanto, también en relación a los contenidos del programa, es muy discutible si el PEIB representa una plataforma favorable para avanzar a una educación intercultural en contexto migratorio.

Al dirigir la mirada hacia dicho contexto, resulta interesante observar que en algunos establecimientos educativos con alto porcentaje de alumnado extranjero los profesores han comenzado a darle espacio justamente a aquellos contenidos que el

23 En la página web del PEIB, estos focos se encuentran formulados de la siguiente manera: "Las iniciativas interculturales que lidera esta coordinación se realizan en base al compromiso de reimpulsar la mejora educativa, orientando y destinando fondos hacia la implementación de la interculturalidad (Sector de Lengua Indígena y talleres de interculturalidad), revitalización lingüística y bilingüismo, y la inclusión del educador/a tradicional al sistema educativo, desde la perspectiva de recuperación de las culturas y lenguas vulneradas de los pueblos originarios en su territorio y a nivel nacional”. Fuente: http://www.peib.cl/index2.php?id_ portal=28\&id_seccion $=5428 \&$ id_contenido $=33816$
PEIB ha promovido explícitamente en los últimos años: lengua y cultura. Dado que la mayor parte de los alumnos migrantes en Chile proviene de países hispanoparlantes, la lengua española es compartida, y no ha sido un gran obstáculo para el proceso de enseńanza-aprendizaje. De todas formas, se ha dado una atención especial a las variaciones del castellano que son diferentes a la variación chilena, y un elemento representativo de ello es la creación de "diccionarios" -iniciativa emprendida por algunas escuelas- que explican por ejemplo que aguacate y palta, tajador y sacapunta, o pena y vergüenza, pueden significar lo mismo. ${ }^{24}$ Por otra parte, en aquellos casos en que la primera lengua de los alumnos migrantes no es el español, a los profesores se les ha presentado un desafío más complejo. En algunos de los establecimientos que cuentan con alumnado haitiano, los municipios están contratando mediadores lingüísticos ${ }^{25}$ (personas que hablan creole y castellano y que contribuyen a la comunicación entre las familias y las escuelas) y recurriendo al uso de diccionarios castellano-creole. ${ }^{26}$

Por otra parte, respecto de la cultura, los colegios han empleado estrategias de tipo folclorístico, como la implementación de las así llamadas celebraciones multiculturales. Estas se expresan en actividades tales como exposiciones gastronómicas de América Latina y el Caribe, presentaciones de bailes, la implementación de un pabellón de diferentes banderas, etcétera (FSP e ICHEM, 2016). Típicamente, las celebraciones multiculturales se realizan en fechas

24 Esta afirmación se basa en resultados preliminares del estudio Fonide.

25 La figura del mediador lingüístico tiene una cierta similitud con la del educador tradicional, un elemento importante en el PEIB. De acuerdo a un estudio del CIAE, en él (o ella) "recae la responsabilidad de la enseńanza de la lengua, y dado que el Educador Tradicional es una persona validada por la comunidad, los niños y niñas logran tener un vínculo de confianza con él (ella) que favorece la enseńanza de la lengua y el traspaso de valores y costumbres culturales" (CIAE, 2011, p. 32).

26 En los últimos años, en Chile se han elaborado al menos dos diccionarios de este tipo: el del Centro Universitario Ignaciano de la Universidad Alberto Hurtado, http://www.uahurtado.cl/wp-images/uploads/2017/01/ annpalepanyol-1.pdf, y el lanzado en agosto del 2017 en la Universidad de Chile: http://www.uchile.cl/noticias/134947/profesor-haitiano-lanzo-diccionario-kreyol-espanol-en-la-u-de-chile 
como el 18 de septiembre, ${ }^{27}$ el 12 de octubre, o para el año nuevo indígena, fechas que en efecto se relacionan con la historia común de los diversos países de América Latina.

Sin embargo, es evidente que ni los diccionarios ni las celebraciones multiculturales aportan verdaderamente a un cambio en las estructuras. Más bien, son respuestas funcionales al sistema; no necesitan de una real transformación de las estructuras para ser llevadas a cabo. Un cambio de esa naturaleza requeriría, por ejemplo, que los profesores tematizaran que la creencia en la superioridad de la cultura y lengua española afecta hasta el día de hoy el bajo prestigio de las lenguas indígenas, que uno de los efectos de los nacionalismos latinoamericanos ha sido suponer que los usos y costumbres propios son mejores que los de los países vecinos, y en general, que la mirada jerarquizada hacia las minorías -que es tan común en América Latina- tiene su origen en un pensamiento colonialista y nacionalista. Por ello, algunos de los contenidos relevantes en una educación intercultural pertinente al contexto migratorio -de los cuales se beneficiarían también los niños de ascendencia indígena- serían por ejemplo un relato de la historia de la conquista de América desde una perspectiva crítica (Todorov, 1985; Dussel, 1994), la inclusión de la historia de la esclavitud, del fenómeno de la migración, y de conocimientos que apunten a una mayor tolerancia a las variaciones del castellano.

\section{Conclusiones}

El presente artículo ha ofrecido un análisis del Programa de Educación Intercultural Bilingüe de Chile para analizar en qué medida dicho programa representa una plataforma favorable para avanzar, desde ahí, a una educación intercultural pertinente al contexto migratorio.

Respecto del grupo objetivo, se describió que en virtud de circunstancias históricas y políticas particulares, el PEIB fue concebido como un beneficio a ser usado exclusivamente por niños de ascendencia indígena -focalización que se ha mantenido hasta la

27 En esta fecha, referida al 18 de septiembre de 1810 , se conmemora la independencia de Chile frente a Espańa. actualidad- $\mathrm{y}$ en sus inicios, sobre todo para nińos del ámbito rural. Al pensar en el traspaso de esa experiencia a una educación intercultural para el contexto migratorio, y considerando tanto las evaluaciones realizadas como los debates que ha generado el programa, actualmente un importante cúmulo de indicios sugiere que la pretensión de avanzar hacia la interculturalidad a través del foco exclusivo en una parte del alumnado representa un sinsentido. La focalización del PEIB en los niños de ascendencia indígena responde a una política educativa de discriminación positiva que hasta cierto punto sería conveniente de aplicar también a los niños migrantes. La investigación ha relevado la necesidad de algunos apoyos pedagógicos dirigidos exclusivamente a los alumnos que han llegado a Chile desde otras partes del mundo -por ejemplo, para los que no hablan castellano-, pero la interculturalidad no se agota en ello. El hecho de que el PEIB -debido al nombre que lleva- reclama para sí mismo el rasgo de ser intercultural, contiene algo de paradoja e induce a confusión. Como hemos expuesto, la educación intercultural, desde la perspectiva de la interculturalidad crítica, debe tener en cuenta "la simetría de los contactos" (Tubino, 2005, p. 88), y es evidente que eso solo se puede lograr cuando se promueve y se resguarda que exista comunicación y diálogo entre los alumnos de diferentes nacionalidades, etnias, lenguas, colores de piel, estratos socioeconómicos, intereses, etcétera.

Esta conclusión tiene ciertas coincidencias con un planteamiento de Fidel Tubino sobre la educación intercultural bilingüe en Perú:

La actual Ley de Educación establece que la Educación Intercultural se debe ofrecer en todo el sistema educativo nacional. Esta oferta global de la Educación Bilingüe Intercultural (EBI) obliga a revisar nuestros presupuestos básicos y nuestras estrategias de intervención. No podemos ni debemos universalizar el modelo de la EBI [...] porque el modelo actual fue diseñado y aplicado para atender a estudiantes indígenas en el nivel primario en zonas rurales (las cursivas son de los autores). El modelo que debemos elaborar ahora para todos debe ser abierto y flexible 
por lo que tiene que contemplar situaciones muy diversas (Tubino, s.f.).

En relación a los contenidos, se expuso que tras un primer período caracterizado por una falta de especificidad, en los últimos años el PEIB explicitó que el foco de sus contenidos estaría puesto en la lengua y la cultura de los pueblos indígenas reconocidos en Chile. Sin embargo, esos contenidos son insuficientes para tematizar la colonialidad del poder; ni los alumnos indígenas ni lo alumnos migrantes verán transformadas las relaciones de poder y las jerarquizaciones al interior de las cuales se encuentran insertos -y donde ocupan el lugar de las minoríasa través del exclusivo abordaje de temas vinculados a lengua y cultura. Los contenidos elegidos por el PEIB hablan mucho más de una interculturalidad funcional que de una interculturalidad crítica, que debe apuntar a cuestionar y desarmar las estructuras existentes. La funcionalidad de los contenidos de lengua y cultura es confirmada por aquellas innovaciones más recurrentes que han emprendido los establecimientos educativos chilenos con alto porcentaje de alumnos migrantes, como lo son por ejemplo las celebraciones multiculturales.

Finalmente, es bastante claro que el PEIB no ha sido suficientemente bien evaluado como para ser considerado un referente válido o legítimo para construir a partir de él un programa de interculturalidad más amplio. Las críticas que se le formulan incluyen el cuestionamiento a la elección de su grupo objetivo, pero también se refieren a múltiples aspectos adicionales de su diseño y su funcionamiento en la práctica.

En definitiva, el análisis de las características del PEIB y la revisión de las evaluaciones que se le han hecho sugiere que es poco conveniente considerar este programa como una plataforma para avanzar a una educación intercultural pertinente al contexto migratorio. Lo anterior implica, para un eventual diseño de una nueva política educativa, no solo tener en consideración la presencia del fenómeno migratorio. Implica además hacerse cargo de que Chile, como toda América Latina, tiene un pasado colonial. Hasta el día de hoy ello ha dejado como herencia, en gran parte de la población, un tipo de pensamiento que no cuestiona la lógica de la colonialidad (Mignolo, 2007, p. 36).
La ausencia de elementos que permitan considerar el programa chileno de educación intercultural bilingüe como una plataforma favorable para transitar hacia una educación intercultural pertinente al contexto migratorio vuelve relevante que la política educativa chilena $-y$ esto posiblemente es relevante también para otros países latinoamericanos- dirija la mirada a las políticas y buenas prácticas del contexto internacional, sobre todo hacia aquellos países que ya tienen un camino recorrido en cuanto a ser países receptores de migración internacional. Existen indicios de que el aparato estatal chileno ya ha comenzado a hacerlo, puesto que en tiempos recientes se han financiado con fondos públicos diversas investigaciones que incluyen revisiones de experiencias internacionales. ${ }^{28}$

Entre las experiencias que los equipos de investigación han destacado se encuentran iniciativas en diversos ámbitos de la política. Sin el afán de presentar aquí una revisión exhaustiva, mencionamos de todas formas algunas de ellas: para comenzar, se propone influir en el reconocimiento de que Chile es un país plurinacional y plurilingüe (tal como lo hizo hace ya varios años Canadá, y más recientemente Bolivia y Ecuador), intencionar que la formación de los docentes -tanto la inicial como la continua- incorpore un enfoque intercultural (como por ejemplo se hace en México, Estados Unidos y Alemania ${ }^{29}$ ),

28 Es el caso de la investigación (FONIDE FX11622) en la cual se enmarca el presente artículo. Los proyectos Fonide reciben financiamiento del Ministerio de Educación de Chile. Un ejemplo de una investigación anterior que también contempló la revisión de literatura internacional es el proyecto FONDECYT 3150512, ejecutado entre 2014 y 2016. Los proyectos FONDECYT reciben financiamiento de la Comisión Nacional de Investigación Científica y Tecnológica (CONICYT), y el proyecto en cuestión se titula "Inmigración y diversidad cultural en los establecimientos educativos chilenos. Acerca de las maneras en que las comunidades educativas enfrentan el desafío de un alumnado crecientemente diverso". A juicio del equipo investigador del proyecto Fonide, las experiencias encontradas sin embargo no corresponden realmente a experiencias de interculturalidad crítica.

29 Los contenidos específicos de una formación docente con enfoque intercultural necesariamente serán diferentes de país en país, de acuerdo a los contextos particulares. En términos generales, y en línea con un libro reciente sobre formación docente editado en Alemania, 
que el currículum se vuelva menos nacionalista (como lo han hecho varias duplas de países, sobre todo europeos, que han elaborado textos escolares bilaterales ${ }^{30}$ ), que se preste una atención especial a la necesidad de niños y nińas de aprender la lengua del país de destino ${ }^{31}$ para un buen desempeño escolar (como se hace en varios países de Europa, como Finlandia, Francia, Espańa, Alemania y Reino Unido) $)^{32}$ y que exista un decidido trabajo a favor de la educación antirracista (como lo hace el proyecto "Escuelas sin racismo - escuelas con coraje", compuesto de una red de escuelas alemanas en varios estados federales). ${ }^{33}$

Antes de terminar, es relevante plantear que las críticas que se han formulado al PEIB evidentemente no solo ponen en tela de juicio su idoneidad para traspasar los lineamientos de este programa a los alumnos extranjeros, sino que, de manera igualmente relevante, cuestionan que sea pertinente mantener dicho programa tal como funciona hoy en día. En este punto, nos parece que son las propias comunidades indígenas las que deberían decidir, caso a caso, si abocarse a mejorar el ya existente PEIB o avanzar hacia formas propias de gestión de la educación, tal como lo hace la escuela reseñada de la región de La Araucanía.

Para finalizar, cabe reiterar que en nuestra opinión la educación con un enfoque intercultural crítico debe apuntar a todas y todos los alumnos del siste-

un docente necesita adquirir dos habilidades básicas para desempeńarse adecuadamente en contextos de diversidad cultural: ser sensible a la diferencia, y ser crítico frente al racismo (Dogmus, Karakasoglu y Mecheril, 2016, pp. 1-9).

30 Para mayor información, ver las descripciones de las comisiones bilaterales de textos escolares, por ejemplo en www.france-allemagne.fr/Das-deutsch-franzosische, $1239 . \mathrm{html}$

31 Dejamos de manifiesto, de todos modos, que todas las lenguas son legítimas y valiosas, y que sería muy fructífero aprovechar también la diversidad de cosmovisiones que las lenguas y sus variaciones implican.

32 Algunos ejemplos concretos de estos dispositivos son los siguientes: en Espańa, existen las Aulas temporales de adaptación lingüística (ATAL), en Alemania, las "clases de bienvenida" ("Willkommensklassen"), y en Reino Unido, los equipos de inglés como lengua adicional ("English as additional language" o EAL).

33 www.schuleohnerassismus.de ma escolar. Esto implica, en primer lugar, una superación del sistema educativo altamente segmentado que existe en Chile, y que es al mismo tiempo reflejo y funcional a una sociedad profundamente atravesada por la lógica neoliberal. Luego, la transición hacia un sistema educativo intercultural se funda en la convicción de que en los tiempos actuales, marcados por una diversificación creciente de la sociedad, una educación de calidad necesita incorporar el aporte de la interculturalidad para cumplir con su cometido. Gunther Dietz plantea que "en el futuro, la mejor educación intercultural va a ser aquella que ya no requiera del adjetivo intercultural, va a ser simplemente una buena educación para todos" (Dietz, 2013). Si bien compartimos esa mirada de futuro, por ahora -tanto en Chile como en los otros países de América Latina- consideramos necesario mantener y relevar el concepto, enfatizando en la pertinencia de su vertiente más crítica.

\section{Agradecimientos}

El presente artículo surge en el marco del estudio "Construyendo escuelas interculturales: elaboración participativa de una hoja de ruta para asistentes de la educación, profesores y directivos", realizado por un equipo de investigación compuesto por profesionales de diferentes universidades, entre diciembre de 2016 y diciembre de 2017. Este proyecto fue financiado por el Ministerio de Educación de Chile, mediante el Fondo de Investigación y Desarrollo en Educación (Código Proyecto: FONIDE FX11622, año 2016).

En la elaboración del artículo contamos con el apoyo de la Pontificia Universidad Católica de Chile, a través de su Centro de Estudios Interculturales e Indígenas (CIIR), proyecto CONICYT/ FONDAP 15110006.

Expresamos nuestro agradecimiento a Sara Joiko, Doctora en Educación por UCL, Institute of Education, por su atenta lectura y sus importantes sugerencias para la versión final de este manuscrito. 


\section{Referencias citadas}

Abarca, G. (2015). Educación Intercultural Bilingüe y los desafíos de su implementación. Cuadernos de Educación, Facultad de Educación, Universidad Alberto Hurtado, 70. Recuperado de http://mailing.uahurtado.cl/cuaderno_ educacion_70/pdf/Apoyo_docente_70.pdf

Acosta, E. (2015). Cuidados en crisis. Mujeres migrantes hacia España y Chile. Universidad de Deusto - Universidad Alberto Hurtado.

Agencia de Calidad de la Educación, OCDE (2015). PISA 2015. Programa para la Evaluación Internacional de Estudiantes OCDE. Agencia de Calidad de la Educación. Recuperado de http://archivos.agenciaeducacion.cl/Resultados_PISA2015.pdf

Aikenhead, G. S. (1997). Toward a First Nations cross-cultural science and technology curriculum. Science Education, 81(2), 217-238.

Arias, M. (2016, diciembre 9). \#NoMásRut100: la campańa por los derechos de los alumnos migrantes en Chile. Elige Educar. Recuperado de http://www.eligeeducar.cl/ nomasrut100-campana-derechos-alumnos-migrantes

Aylwin, J. (2013). Presentación. En Los pueblos indígenas y el derecho (pp. 29-40). Santiago de Chile: LOM Ediciones - Observatorio Ciudadano.

Battiste, M. y Barman (Eds.). (1995). First nations education in Canada: the circle unfolds. Vancouver: UBC Press.

Bengoa, J. (1999). Historia de un conflicto. El Estado y los mapuches en el siglo XX. Santiago de Chile: Editorial Planeta.

Bengoa, J. (2004). La memoria olvidada: historia de los pueblos indigenas de Chile. Santiago: Cuadernos Bicentenario Presidencia de la República.

Beniscelli, L. (2016). "Nos estamos llenando de extranjeros”. Racismo cotidiano en los discursos de laslos maestros de una escuela con niñas y niños migrantes en la comuna de Santiago (Tesis de maestría). FLACSO Argentina, Buenos Aires.

Bisquerra Alzina, R. (Ed.). (2009). Metodología de la investigación educativa (2a ed.). Madrid: Editorial La Muralla.
Boccara, G. y Ayala, P. (2011). La nacionalización del indígena en tiempos de multiculturalismo neoliberal. fiar, 4(2). Recuperado de http://interamerica.de/volume-4-2/ boccaral

Bustos, R. y Gairín, J. (2017). Adaptación académica de estudiantes migrantes en contexto de frontera. Calidad en la educación, 46, 193-220.

Canales, A. y Zlolniski, C. (2001). Comunidades transnacionales y migración en la era de la globalización. Notas de Población, 28(73), 221-252.

Castles, S. y Miller, M. (2004). La era de la migración: movimientos internacionales de población en el mundo moderno. México DF: Universidad Autónoma de Zacatecas.

Cayuqueo, P. (2015, junio 24). "Un nuevo amanecer para todos”. La Tercera. Recuperado de http://www.latercera. com/voces/un-nuevo-amanecer-para-todos/

CIAE (2011). PEIB-ORÍGENES. Estudio sobre la implementación de la Educación Intercultural Bilingüe. Santiago (Chile): Ministerio de Educación.

Coñuepán, V. y Lemunguier, L. (s.f.). Memorias de la labor de la Dirección de Asuntos Indígenas de Chile 1953-1959 (documentos compilados y transcritos por Alejandro Clavería, Jorge I. Vergara y Rolf Foerster). Recuperado de http:// www.desclasificacion.org/pdf/Memorias_Dasin.pdf

Correa, M. (2016, septiembre 14). \#NoMasRUT100 porque en Chile nadie sobra. El Desconcierto. Recuperado de http://www.eldesconcierto.cl/2016/09/14/nomasrut100porque-en-chile-nadie-sobra/

Correa Téllez, J. (2016). La Inmigración como "problema” o el resurgir de la raza. Racismo general, racismo cotidiano y su papel en la conformación de la nación. En Tijoux, M. E. (Ed.). Racismo en Chile. La piel como marca de la inmigración (pp. 35-47). Santiago: Editorial Universitaria.

DAEM Temuco (2016). Azumkantuaiñ fill mogen kimün. Hacia la interculturalidad. Recuperado de http:// portales.mineduc.cl/usuarios/intercultural/File/2017/ Libro-Educacion-Intercultural-Azumkantuain-Fill-Mogen-Kimun.pdf

Dietz, G. (2013). "La mejor educación intercultural va a ser aquella que ya no requiera del adjetivo intercultural". Entrevista a Gunther Dietz. Docencia, 51, 18-25. 
Dogmus, A., Karakasoglu, Y. y Mecheril, P. (Eds.). (2016). Pädagogisches Können in der Migrationsgesellschaft. Wiesbaden: Springer VS.

Donoso, A., Mardones, P. y Contreras, R. (2009). Propuestas y desafíos a partir de la experiencia de una escuela con migrantes en el Barrio Yungay, Santiago de Chile. Docencia, 37, 56-62.

Dussel, E. (1994). 1492. El encubrimiento del otro. Hacia el origen del mito de la modernidad. La Paz: Plural Editores.

Elizalde, A., Thayer, E. y Córdova, M. G. (2013). Migraciones sur-sur: paradojas globales y promesas locales. Polis, 35.

Falabella, A. (2015). El mercado escolar en Chile y el surgimiento de la nueva gestión pública: el tejido de la política entre la dictadura neoliberal y los gobiernos de la centroizquierda (1979 a 2009). Educação \& Sociedade, 36(132), 699-722.

Gobierno de Chile (1993). Ley 19.253.

Hale, C. R. (2002). Does Multiculturalism Menace? Governance, Cultural Rights and the Politics of Identity in Guatemala. Journal of Latin American Studies, 34(3), 485-524.

Hernández, R. (2004). Evaluación de la eficiencia programática y la pertinencia intercultural del Programa de Educación Intercultural Bilingüe del Ministerio de Educación en escuelas de la Región Metropolitana (p. 107). Santiago de Chile: Universidad de Chile, Facultad de Ciencias Sociales, Departamento de Antropología. Recuperado de http://www.opech.cl/bibliografico/Participacion_Cultura_Escolar/Evaluacion_PEIB_en_Metropolitana.pdf

Hevia, R. e Hirmas, C. (2005). La política de Educación Intercultural y Bilingüe en Chile en el marco de las políticas de atención a la diversidad cultural. En Seminario Internacional Pueblos Indigenas Afrodescendientes de América Latina y el Caribe: relevancia y pertinencia de la información sociodemográfica para politicas y programas. CEPAL. Santiago de Chile: Unesco. Recuperado de http://centroderecursos.cultura.pe/sites/default/files/rb/ pdf/La\%20politica\%20de\%20educacion\%20intercultural\%20y\%20bilingue $\% 20$ en $\% 20$ Chile.pdf

Huddleston, T., Niessen, J., Ni Chaoimh, E. y White, E. (2011). Index Integration und Migration III. Bruselas:
British Council, Migration Policy Group. Recuperado de www.mipex.eu

Huenchullán Arrué, C. (2017). Pedagogía decolonial: intersecciones y resistencias de la memoria y la historia, en comunidades mapuche del sur de Chile. En Plá, S. y Rodríguez Ávila, S. P. (Eds.). Saberes sociales para la justicia social: educación y escuela en América Latina (pp. 71-98). Bogotá: Universidad Pedagógica Nacional.

Instituto Nacional de Estadísticas (2017). Segunda entrega resultados definitivos Censo 2017. Recuperado de http://www. censo2017.cl/wp-content/uploads/2018/05/presentacion_ de_la_segunda_entrega_de_resultados_censo2017.pdf

Jiménez, F. (2014). Modelos de gestión de la diversidad cultural para la escolarización de alumnado inmigrante en las escuelas chilenas: Desafíos para la interculturalidad actual. Estudios Pedagógicos, XL(2), 409-426.

Jiménez, F., Aguilera, M., Valdés, R. y Hernández, M. (2017). Migración y escuela: Análisis documental en torno a la incorporación de inmigrantes al sistema educativo chileno. Psicoperspectivas, 16(1), 105-116.

Jiménez, F. y Fardella, C. (2015). Diversidad y rol de la escuela. Discursos del profesorado en contextos educativos multiculturales en clave migratoria. Revista Mexicana de Investigación Educativa, 20(65), 419-441.

Johnson, D. (2015). Formar ciudadanos interculturales en un mundo global: algunas notas desde los estudios curriculares. Diálogo Andino, 47, 7-14.

Joiko, S. (2012). El cuasi-mercado educativo en Chile: desarrollo y consecuencias. Revista Electrónica Diálogos Educativos, 12(23), 148-174.

Joiko, S. y Vásquez, A. (2016). Acceso y elección escolar de familias migrantes en Chile: "no tuve problemas porque la escuela es abierta, porque acepta muchas nacionalidades“. Calidad en la educación, 45, 132-173.

Joiko, S. y Vásquez, A. (2017). Familias migrantes y elección escolar en Chile. Santiago. Recuperado de http://www. infanciasincondiciones.cl/wp-content/uploads/2017/06/ Familias-migrantes-y-eleccion-escolar-en-Chile.pdf

Koopmans, R. (2013). Multiculturalism and Immigration: A Contested Field in Cross-National Comparison. Annual Review of Sociology, 39, 147-169. 
Kymlicka, W. (1996). Ciudadanía multicultural. Una teoría liberal de los derechos de las minorias. Barcelona: Paidós.

Lagos, C. (2015). El Programa de Educación Intercultural Bilingüe y sus resultados: ¿perpetuando la discriminación? Pensamiento Educativo. Revista de Investigación Educacional Latinoamericana, 52(1), 84-94.

Le Bert, J. M., Winchester, L. y Caro, J. C. (2004). Informe final de evaluación Programa Origenes. Ministerio de Planificación y Cooperación. Ministerio de Planificación y Cooperación. Recuperado de http://www.dipres.gob. cl/595/articles-139541_informe_final.pdf

López, L. E. y Küper, W. (2002). La Educación Intercultural Bilingüe en América Latina. Balance y Perspectivas. GTZ.

Mardones, P. (2006). Exclusión y sobre-concentración de la población escolar migrante bajo un modelo de segregación socio-territorial (Informe final del concurso). Argentina: CLACSO. Recuperado de http://bibliotecavirtual.clacso. org.ar/ar/libros/becas/2005/2005/migra/mardones.pdf

Marín, J. (2014). Hijos de inmigrantes en el norte de Chile: Hacia la construcción de una escuela intercultural (Magíster en Ciencias Sociales Aplicadas). Universidad de Tarapacá, Iquique, Chile. Recuperado de http://www.observatoriocultural.gob.cl/haz-tu-tesis-en-cultura/2014/

Marroquín, A. D. (1977). Balance del indigenismo (1ª ed., $2^{a}$ impr.). México, DF: Inst. Indigenista Interamericano.

Martínez, J. (Ed.). (2011). Migración internacional en América Latina y el Caribe. Nuevas tendencias, nuevos enfoques. Santiago: CEPAL.

Martínez, J. y Orrego, C. (2016). Nuevas tendencias y dinámicas migratorias en América Latina y el Caribe (Población y Desarrollo) (p. 107). Santiago de Chile: CEPAL.

Meza-Lopehandía, M. (2013). El Convenio N¹69 sobre pueblos indígenas y tribales de la Organización Internacional del Trabajo. En Aylwin, J. (Ed.). Los pueblos indígenas y el derecho (pp. 337-439). Santiago: LOM Ediciones.

Mignolo, W. (2007). La idea de América Latina. La herida colonial y la opción decolonial. Barcelona: Gedisa.

Ministerio de Educación. Decreto Supremo No 651 de 1995 (1995). Recuperado de http://portales.mineduc.cl/transparencia/marco_normativo.html
Ministerio de Educación. Ley General de Educación, Pub. L. No 20.370 (2009). Recuperado de http://www.leychile.cl/Navegar?idNorma $=1006043$

Ministerio de Educación. Ley de Inclusión Escolar, Pub. L. No 20.845 (2017). Recuperado de https://www.leychile. $\mathrm{cl} /$ Navegar?idNorma $=1078172$

Ministerio de Educación (2017b). Orientaciones técnicas para la inclusión educativa de estudiantes extranjeros. División de Educación General.

Ministerio de Educación (2018a). Mapa del estudiantado extranjero en el sistema escolar chileno (2015-2017). Centro de Estudios Mineduc.

Ministerio de Educación (2018b). Política Nacional de Estudiantes Extranjeros 2018-2022. Mineduc. Recuperado de https://migrantes.mineduc.cl/wp-content/uploads/sites/88/2018/06/POLITICA-NACIONAL-EE-Final-1-1. pdf

Molina, P. (2015). Significación de la vida escolar de los niños y niñas de origen peruano en 4 escuelas de Santiago (Memoria para optar al título profesional de Sociólogo). Universidad de Chile, Santiago.

Palaiologou, N. y Dietz, G. (Eds.). (2012). Mapping the broad field of multicultural and intercultural education worldwide: Towards the development of a new citizen. Newcastle upon Tyne: Cambridge Scholars Publishing.

Palma, J. y Joiko, S. (2016). "Niños RUT 100 millones: políticas provisorias y exclusión de migrantes". El Dínamo. Recuperado de http://www.eldinamo.cl/blog/los-ninosrut-100-millones-politicas-provisorias-y-exclusion-delos-estudiantes-migrantes/?ref=linkmovilcontenido

Pavez, I. (2012). Inmigración y racismo: experiencias de la niñez peruana en Santiago de Chile. Si somos americanos. Revista de Estudios Transfronterizos, XII(1), 75-99.

Pinto, J. (2003). La formación del Estado y la nación, y el pueblo mapuche. De la inclusión a la exclusión. Santiago de Chile: DIBAM, Centro de Investigaciones Diego Barros Arana.

Pinto, R., Calfuqueo, J., Painequeo, H., Silva, A., Cubillos, F., Berríos, R. y Cuerpo Docente (2011). Matriz de diseño curricular para la escuela básica Kom Pu Lof Ni Kimeltuwe, de lago Budi, Llaguepulli. Región de La 
Araucanía. Universidad Metropolitana de Ciencias de la Educación.

Poblete, R. (2009). Educación Intercultural en la Escuela de hoy: reformas y desafíos para su implementación. Revista Latinoamericana de Educación Inclusiva, 3(2), 181-200.

Quijano, A. E. (2001). Colonialidad del poder, cultura y conocimiento en América Latina. Peru contemporáneo: revista de historia y sociedad, 7-19.

Ramírez, M. T. y Miranda, F. (2018). Diálogos para la inclusión de estudiantes extranjeros. Informe de devolución. Ministerio de Educación. Recuperado de www. migrantes.mineduc.cl

Riedemann, A. (2008). La Educación Intercultural Bilingüe en Chile: ¿Ampliación de oportunidades para alumnos indígenas? Indiana, 25, 169-193.

Riedemann, A. y Stefoni, C. (2015). Sobre el racismo, su negación, y las consecuencias para una educación antiracista en la enseñanza secundaria chilena. Polis, 42.

Rinke, S. (2002). Cultura de masas, reforma y nacionalismo en Chile 1910-1931. Santiago, Chile: DIBAM.

Rivas, F. (2015, mayo 13). "Chile tiene la mejor educación de América Latina, según ranking de la OCDE”. Radio Bío-Bío. Recuperado de http://www.biobiochile.cl/noticias/2015/05/13/chile-tiene-la-mejor-educacion-de-america-latina-segun-ranking-de-la-ocde.shtml

Rojas, N. y Silva, C. (2016). La migración en Chile: breve reporte y caracterización (p. 44). Madrid: Observatorio Iberoamericano sobre Movilidad Humana, Migraciones y Desarrollo. Recuperado de http://www.comillas.edu/ es/obimid

Román, M. y Corvalán, J. (2016). “Dicen que esta escuela es mala, pero nosotros la encontramos buena”. Elección de escuela en familias pobres en Chile. En Mercado escolar y oportunidad educacional (pp. 209-231). Santiago: CEPPE-UC.

Sánchez, A., Navas, L. y Holgado, P. (2013). Inmigración y educación intercultural en la formación inicial docente. Estudios Pedagógicos, XXXIX(1), 239-251.

Sepúlveda, P. (2016, abril 15). "Chile es el país de peor desempeño en educación en la OCDE”. La Tercera. Re- cuperado de http://www.latercera.com/noticia/chile-esel-pais-de-peor-desempeno-en-educacion-en-la-ocde/

Stang, F. (2016). Algunas notas sobre el marco normativo de las migraciones en Chile, con énfasis en la dimensión educativa (inédito).

Stefoni, C. (2011). Mujeres inmigrantes en Chile. Santiago: Ediciones Universidad Alberto Hurtado.

Stefoni, C., Acosta, E., Gaymer, M. y Casas-Cordero, F. (2008). Niños y niñas inmigrantes en Santiago de Chile. Entre la integración y la exclusión. OIM- UAH.

Stefoni, C., Stang, F. y Riedemann, A. (2016). Educación e interculturalidad en Chile: un marco para el análisis. Estudios Internacionales, 185 (Número especial), 153182.

Subsecretaría de Educación. Oficio 894 (2016). Recuperado de http://www.comunidadescolar.cl/documentacion/2016/ORD_894_Estudiantes_migrantes.pdf

Tijoux, M. E. (2013a). Las escuelas de la inmigración en la ciudad de Santiago: Elementos para una educación contra el racismo. Polis, 12(35), 287-307.

Tijoux, M. E. (2013b). Niños(as) marcados por la inmigración peruana: estigma, sufrimientos, resistencias. Convergencia, 61, 83-104.

Tijoux, M. E. y Palominos, S. (2015). Aproximaciones teóricas para el estudio de procesos de racialización y sexualización en los fenómenos migratorios de Chile. Polis, $14(42), 247-275$.

Todorov, T. (1985). Die Eroberung Amerikas. Frankfurt a. M.: Suhrkamp.

Tubino, F. (s.f.). Interculturalidad para todos. ¿Un slogan más? Recuperado 18.05.2017 de http://aulaintercultural. org/2005/02/15/interculturalidad-para-todos-un-sloganmas/

Tubino, F. (2005). La praxis de la interculturalidad en los Estados Nacionales Latinoamericanos. Cuadernos Interculturales, 3(5), 83-96.

Universidad de Chile (2015). Recomendaciones de Políticas Públicas contra el Racismo en Chile. Departamento de Sociología, Facultad de Ciencias Sociales. Recupera- 
do de http://www.uchile.cl/portal/extension-y-cultura/ vicerrectoria-de-extension-y-comunicaciones/catedrade-derechos-humanos/113362/seminario-racismo-enchile

Valenzuela, J. P., Bellei, C. y De los Ríos, D. (2013). Socioeconomic school segregation in a market-oriented educational system. The case of Chile. Journal of Education Policy, 29(2), 217-241.
Walsh, C. (2010). Interculturalidad crítica y educación intercultural. En Construyendo interculturalidad crítica (pp. 75-96). La Paz: Instituto Intercultural de Integración. Recuperado de http://aulaintercultural.org/2010/12/14/ interculturalidad-critica-y-educacion-intercultural/

Williamson, G. (2012). Institucionalización de la educación intercultural bilingüe en Chile. Notas y observaciones críticas. Perfiles educativos, XXXIV(138), 126-147. 